\title{
Breast Tuberculosis in Man a Very Rare Entity
}

Hamid Asmouki ${ }^{1}$, Dr. Oussama Rachid ${ }^{2 *}$, Dr. Khadija Najmeddine ${ }^{2}$, Abderraouf Soummani ${ }^{1}$

${ }^{1}$ Professor, Department of Obstetrics and Gynecology, Hospital University Mohammed VI Cadi Ayyad University, Marrakech, Morocco

${ }^{2}$ Department of Obstetrics and Gynecology, Hospital University Mohammed VI Cadi Ayyad University, Marrakech, Morocco

DOI: $10.36347 /$ simcr.2020.v08i02.023

| Received: 10.02.2020 | Accepted: 17.02.2020 | Published: 21.02.2020

*Corresponding author: Dr. Oussama Rachid

Abstract

Breast tuberculosis in man is exceptional, even in endemic countries. It is an unusual presentation both clinically and radiologically leading into numerous differential diagnostic, including pyogenic abscess and cancer. The treatment of choice is chemotherapy. We are describing a rare case of a young healthy male with no other supposed localizations of tuberculosis or any immunodeficiency.

Keywords: Breast, tuberculosis, man, malignancy.

Copyright @ 2020: This is an open-access article distributed under the terms of the Creative Commons Attribution license which permits unrestricted use, distribution, and reproduction in any medium for non-commercial use (NonCommercial, or CC-BY-NC) provided the original author and source are credited.

\section{INTRODUCTION}

Despit the fact that tuberculosis is increasing all over the world, breast tuberculosis is very rare. It represents less than $0.1 \%$ of all breast diseases surgically treated in western countries and between $0.64 \%$ and $4 \%$ of all mammary conditions in India [15].

This may be explained by a noticeable resistance of the mammary tissue to the mycobacterium tuberculosis $[2,6]$.

It occurs more frequently in women, especially during reproductive age, due to lactation, and is uncommon in prepubescent and elderly women. It is generally though that in pregnant and lactating women, the increased vascularity of the breast with dilated ducts can predispose to tubercular infection [2, 4, 6-8].

BT has no defined clinical features. The multiple presentations of this disease are often confused with either breast benign fibroid, abscess or carcinoma of the breast. Mammography has also limited role in the diagnosis [4].

The most common symptom is a lump in the breast along with pain; witch was present in our case. Pain is usually not a feature in cases of carcinoma [2, 8].

We report a case of mammary Tuberculosis and contralateral lymphadenitis in young man.

\section{Case Presentation}

A 34 years old men, professor, non smoker, presented a painful retro-areolar tumor of his right breast, $1 \mathrm{~cm}$ in diameter, slightly squamous on the surface. There was no nipple discharge from either breast but there were enlarged lymph node of $2 \mathrm{~cm}$, firm and mobile, in the left axilla without any discharge. There were no other complaints, No suggestive history of tuberculosis was declared with a good overall physical condition. Serology assays was not demanded as the patient didn't present risk factors

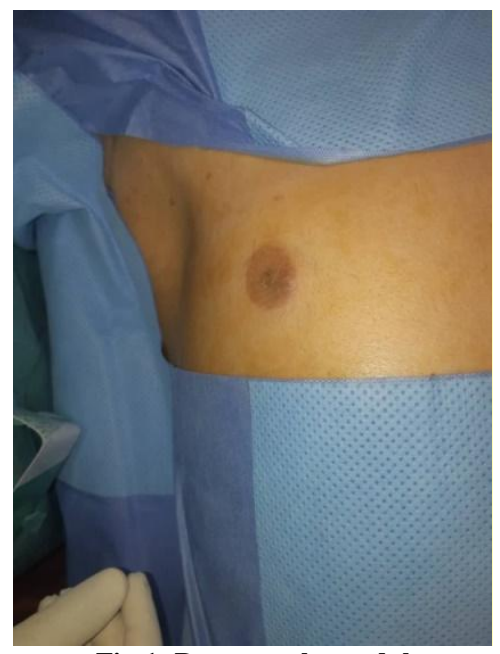

Fig-1: Retro areolar nodul

Sonography revealed a hypoechoic nodular image of $19 * 9 \mathrm{~mm}$, well defined, located at mammary tissue. 


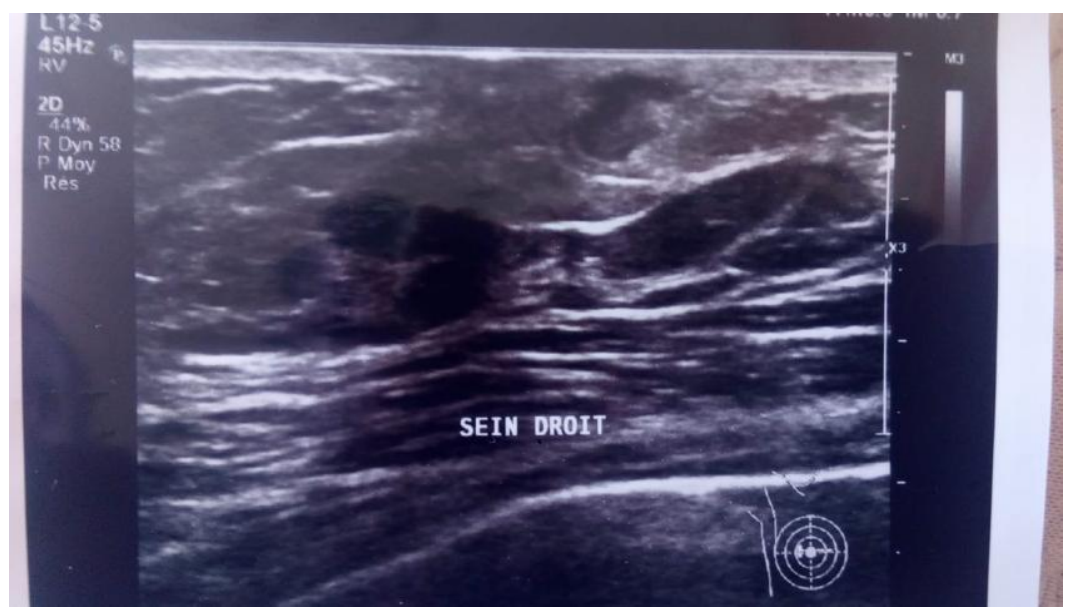

Fig-2: Hypoechoic nodular image

Paget disease and breast cancers were discussed first because of the squamous appearance of the right breast.

Execionnal biopsy was performed removing the lump and the covering part of the nipple areola complex, lymph node dissection of the left axilla reveals a magma of a firm erythematous lymph nodes.

The biopsy revealed the presence of chronic granulomatous mastitis and lymph node tuberculosis with caseous necrosis. There was no evidence of atypical epithelial hyperplasia or malignancy.

Throughout investigation for $\mathrm{TB}$ in other organs was negative, He performed CT scan, sputum smear.

\section{Traitement}

The patient was put on a 6-month course of anti-tubercular therapy with a 2 month intensive phase of rifampicin, isoniazid, ethambutol, and pyrazinamide followed by a consolidation phase of rifampicin and isoniazid for another 4 months.

\section{DiscussiOn}

Tuberculosis of the breast, is a rare affection, occurs in developing countries, known being in high endemic rate. Male patients were reported just in few cases. In 2018 Quaglio et al., [5] reveald in a systematic review of the literature including reports published in English, Spanish and French until December 2017, 26 cases of male breast tuberculosis, the median age was 56.5 years. Most presented with an isolated breast lump $(89 \%)$, associated with axillary lymphadenitis $(27.8 \%)$ witch is our case too.

Exceptionally, it may present as bilateral breast masses, a unilateral mass with bilateral axillary swellings, or as a recurring breast abscess. It may coexist with malignancy [9]. It may occur as a primary lesion, without any preceding history suggesting tuberculosis elsewhere in the body, or as a secondary manifestation. The literature cannot decide if primitive or secondary breast tuberculosis is more frequent $[2,7]$.

It should be considered in the differential diagnosis of all cases of primary pulmonary tuberculosis together with a breast lump and especially where fine needle aspiration cytology has failed to reveal the expected tumour cells.

There are three recognised modes of spread of tuberculosis to the breast: haematogenous, lymphatic and by direct extension [7].

The particular about the case of our patient is that the lump is controlateral relatively to the axillary lymph node involved; it may suggest that the mechanism involved is lymphatic spreading, but we can't propose the primitive location of the disease, breast or lymph nod tuberculosis

Mckeown et al., in 1952 classifying BT into five categories [10] by form, importance and implications. We suggest that a the time of this classification, tuberculosis and breast tuberculosis was more frequent, more endemic, and accessibility to treatment was limited, it is also not a reference for men breast tuberculosis. Mehta et al., [11] equally made a newer classifaction in 2010, but again, we cannot make such a correspondence to breast form men and anterior chest wall.

However, Breast TB is often difficult to diagnose in both genders. Radiology is unspecific, Coexistent pulmonary TB may be suggestive of breast $\mathrm{TB}$, but active disease is often absent [6-8].

It is not a big deal, because anyway we have to, according to the presentation, have a histoligical proof, by biopsy or by fine needle aspiration.

The positive diagnostic is the same as any tubercolusis location, confirmed by the finding of epitelioid granulomatosis and caseous necrosis. 
The treatment of choice is chemotherapy for at least six months, surgery being reserved for residual masses or drainage $[3,6,7]$.

\section{Conclusion}

BT in men is very rare localization, clinician have to be aware of, particularly in endemic region. The most common presentation is a lump, chemotherapy has a satisfactory responses and overall prognosis is good. A men presenting breast pain or a limb has to be taking seriously.

\section{REFERENCES}

1. Gon S. Tubercular Mastitis-A Great Masquerader/Tüberküloz Mastiti-Büyük Taklitçi. Turkish Journal of Pathology. 2013 Mar 1;29(1):61-3.

2. Marinopoulos S, Lourantou D, Gatzionis T, Dimitrakakis C, Papaspyrou I, Antsaklis A. Breast tuberculosis: Diagnosis, management and treatment. International journal of surgery case reports. 2012 Jan 1;3(11):548-50.

3. Gupta R, Singal RP, Gupta A, Singal S, Shahi SR, Singal R. Primary tubercular abscess of the breastan unusual entity. Journal of medicine and life. 2012 Feb 22;5(1):98-100.
4. Shrestha A, Gautam K, Pyakurel D, Pradhan S, Pant V. Breast tuberculosis, a rare entity. IDCases. 2019 Jan 1;15:e00530.

5. Quaglio G, Pizzol D, Bortolani A, Manenti F, Isaakidis $\mathrm{P}$, Putoto $\mathrm{G}$, Olliaro PL. Breast tuberculosis in men: A systematic review. PloS one. 2018;13(4): e0194766.

6. Bouhout T, Serji B, Egyir EU, Amri BE, Bouhout I, Soufi M, Bouziane M, Harroudi TE. Breast tuberculosis: about a case. Pan African Medical Journal. 2017 Oct 27;28:183.

7. Brown S, Thekkinkattil DK. Tuberculous cold abscess of breast: an unusual presentation in a male patient. Gland Surgery 2016;5(3):361-365.

8. Fatima K, Naz F. Tuberculosis of Male Breast: A Rare Benign Entity. Cureus. 2019;11(5):e4709.

9. Sinha RT, Dey A, Agarwal S. Tuberculous mastitis diagnosed on cytology-case report of a rare entity. Journal of cytology. 2017 Jul;34(3):162-164.

10. McKeown KC, Wilkinson KW. Tuberculous disease of the breast. British Journal Surgery, 1952;39:420.

11. Mehta G, Mittal A, Verma S. Breast tuberculosisclinical spectrum and management. Indian Journal of Surgery. 2010 Dec 1;72(6):433-7. 